\title{
NDC UN (Unit)
}

National Cancer Institute

\section{Source}

National Cancer Institute. NDC UN (Unit). NCI Thesaurus. Code C155839.

A recognized billing qualifier that may be used to identify a unit as the NDC unit of measure. This is often used when describing a powder for injection (needs to be reconstituted), pellet, kit, patch, tablet or device. 